\title{
Uterovaginal prolapse following suspected sexual abuse to a child: a case report
}

\author{
Odion-Obomhense Kesiena Helen ${ }^{1^{*}}$ (D), Ntaji Maureen Iru², Ekpebe Patrick Akpofure ${ }^{3}$ and Afeyodion Akhator ${ }^{1}$
}

\begin{abstract}
Background: Uterovaginal prolapse occurs when damaged connective tissues allow the uterus to drop into the vagina. Rare in children, uterovaginal prolapse can occur as a result of violent sexual assault. This case is being reported because there has been no previous report of acquired pelvic organ prolapse following trauma suspected to be sexual abuse in a child in our setting.

Case presentation: Two-year-old female presented to our hospital with a 3-day history of abnormal protrusion from the vagina and a 2-day history of bleeding per vagina. Traumatic rupture of the hymen was observed. The urethra was not edematous or hyperemic. The reduction was done successfully under sedation and maintained using a crepe bandage. There was no recurrence after 3-month follow-up.

Conclusions: Uterovaginal prolapse presenting among children below 5 years is rare. If bleeding per vagina is reported in a child, the clinician should be aware of the possibility of uterovaginal prolapse.

Keywords: Uterovaginal prolapse, Child, Sexual abuse, Case report
\end{abstract}

\section{Background}

Uterovaginal prolapse (UVP) is a condition whereby the uterus drops into the vagina and may prolapse through the introitus [1]. This is due to damaged or weakened muscles and connective tissues such as the ligaments which support it [2]. It can be congenital or acquired. Both forms are quite rare in children with research articles describing more of the congenital presentations in children, the congenital presentation being more frequent than the acquired and usually associated with spinal cord defects $[3,4]$. The etiology of the congenital form is due to congenital weakness of the pelvic floor or abnormal nerve supply to the pelvic floor [5]. Acquired presentation is extremely rare, particularly below 5 years. The acquired presentation can occur as a result of violent sexual assault or repeated sexual abuse [6, 7]. In recent times, several reports from all over the world have made it obvious that child sexual abuse is more common

\footnotetext{
* Correspondence: drkesoghene@gmail.com

'Department of Surgery, Delta State University Teaching Hospital, P.M.B 07, Oghara, Delta State, Nigeria

Full list of author information is available at the end of the article
}

than congenital heart disease, childhood cancer, and juvenile diabetes combined [8]. Due to not being able to vocalize if abuse has occurred or not in toddlers, clinical findings that are suspected of abuse are looked out for in the genital area. Most of this finding is found in the posterior area of the hymen. Such findings are the interruption of the peripheral edge of the hymen at the region between three and nine o'clock position [9]. The trauma will result in the posterior notch of the hymen appearing V-shaped rather than semilunar shaped [8]. However, these are nonspecific findings. From research articles reviewed, the only facts that are consistent with findings of sexual abuse are reported pain, vaginal bleeding, and elapsed time since traumatic event [10].

Uterovaginal prolapse is well documented in older women with multiple childbirths [11]. Other causes of it are menopause, persistent coughing, and lifting of heavy objects, obesity, and previous surgeries [12]. All of these have been very well documented in adults.

However, for uterovaginal prolapse to occur in a child who had no previous history of the congenital form, the trauma to the pelvic floor of the child would be like the 
trauma of vaginal deliveries or pelvic surgeries that damaged the levator ani muscle. This assumption is because, from several research articles reviewed, the pelvic muscle that is injured is said to be levator ani $[13,14]$.

To the best of our knowledge, in our setting, there has been no previous report of pelvic organ prolapse following suspected sexual abuse in a child. We believe that reporting this case report will bring awareness to clinicians managing a child with vaginal bleeding to have uterovaginal prolapse as a differential diagnosis and if found to be so, it should be promptly reduced to prevent continuous exposure of the mucosa which can predispose it to not only injury but subsequent metaplasia from prolonged exposure.

\section{Case presentation}

A 2-year-old female residing with her parents was brought to the children's emergency with a 3-day history of a protrusion from the vagina and a 2-day history of persistent bleeding from the vagina. The abnormal protrusion was first noticed by the mum when she observed that the toddler kept touching her vulva and decided to examine it, she described it as a pinkish swelling with no change in size since she observed it, and she described it as a size of a walnut. No such history of protrusion was observed before. No swelling was observed elsewhere in the body. Mum did not observe any fall astride or history of trauma. No foul smell was observed from the mass. There was also no history of hematuria. Bleeding was noticed a day after mum observed the protrusion from the vagina. It was initially profuse, but it progressively reduced till presentation. At the time of presentation, she was said to be spotting blood. Blood was characterized as fresh with no associated clots. No bleeding was observed in any other part of her body, and there was no family history of bleeding disorder. There was no history of dizziness or fainting spells. There was also a history of restlessness and discomfort; there was however no history of dysuria or urinary retention, any incontinence, hematuria, or vaginal discharges. There was also no history of constipation or straining to stool. The parents denied toddler been left with anyone other than themselves before the onset of bleeding and protruding mass was seen.

At the onset of symptoms, parents took the child to a private hospital where a diagnosis of a vaginal polyp was made before she was referred to us. When examined in our facility, it revealed a female toddler who was restless and not wanting to walk or play. Her perineum was stained with blood. When the labia minora was parted, it was observed that her vulva was edematous with a fleshy, hyperemic circumferential mass protruding from the vaginal orifice. The mass was continuous with the adjacent labia minora (Fig. 1a, b). There was a traumatic rupture of the hymen evidenced by the inner aspect of the wall of the mass having rugae and a V-shaped configuration of the hymen.

The urethral opening was neither edematous nor hyperemic and was located separately from the mass. The anus was patent with a normal sphincter tone; the gloved finger was stained with brown stools and was not bloody. No presacral dimples were observed.

No masses were palpated on abdominal examination. Lower limbs, sensation, and cardiovascular and respiratory system review were all normal for her age. Abdominopelvic ultrasound scan done showed no intraabdominal or pelvic mass, also showed nothing suggestive of internal bleeding. An assessment of uterovaginal prolapse following suspected trauma which we thought was most likely sexual abuse was made based on the above findings.

After obtaining consent from parents, manual reduction was done under sedation with reduction maintained with a crepe bandage, done in a mermaid fashion sparing the anus for defecation (Fig. 2a, b, c). This was done by manual digital reduction and then strapping the legs

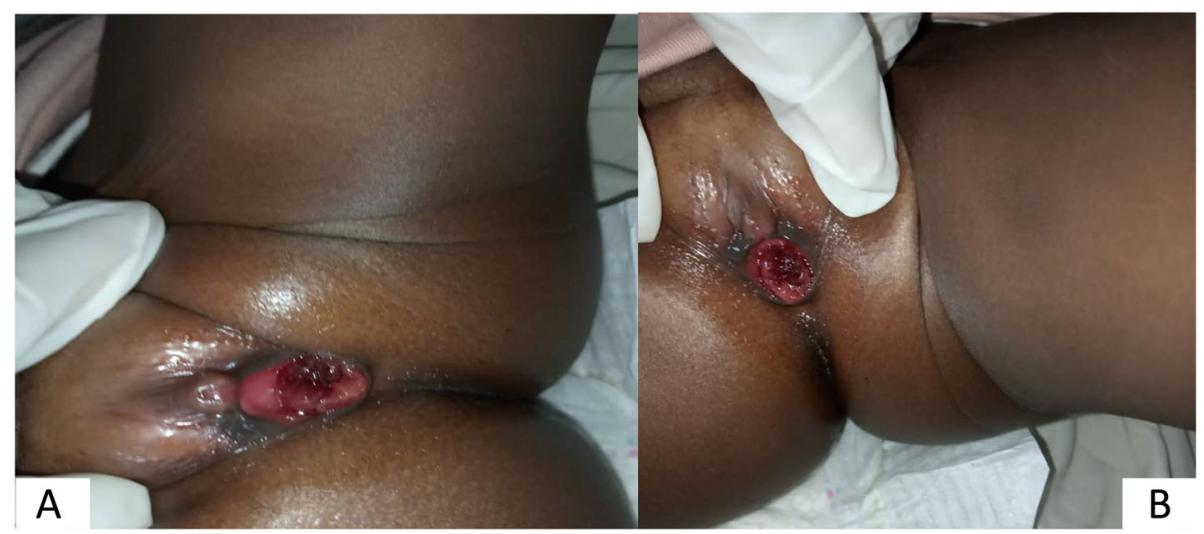

Fig. 1 a Picture of uterovaginal prolapse in transverse view. b Picture of uterovaginal prolapse in longitudinal view 


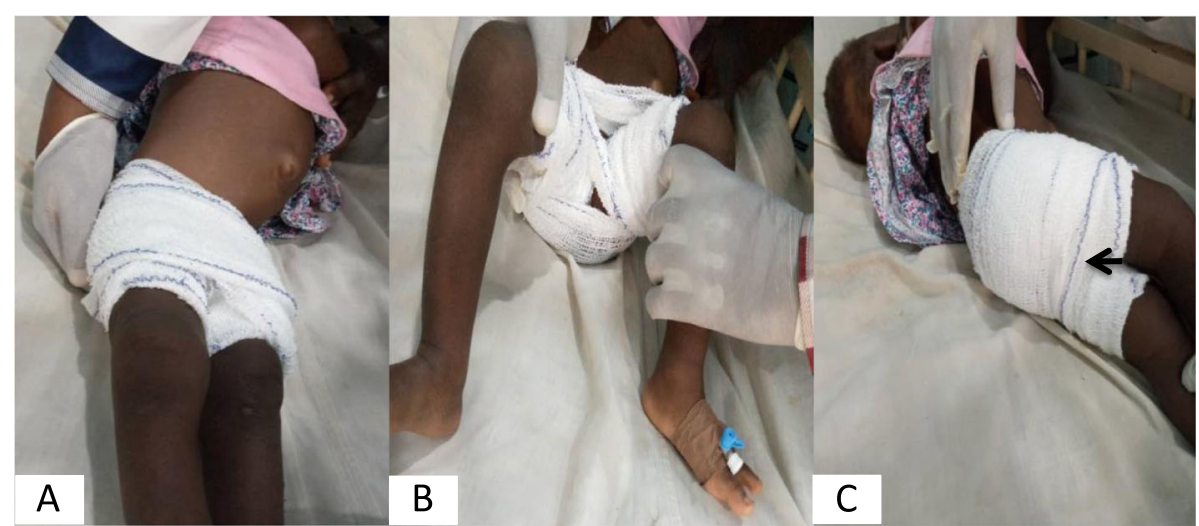

Fig. 2 a, b A picture of mermaid pattern

together with a crepe bandage so that the limbs appeared fused together like that of a mermaid. The crepe was removed after $72 \mathrm{~h}$, and the prolapse genitals remained reduced though she still had occasional spotting of blood from the vagina. Retroviral prophylaxis and antibiotics were given. The parents expressed shock when findings and diagnosis were made as they initially thought it was a vaginal tumor. The parents became agitated and requested to go home immediately and continue care from home. They went home with instructions on how to give oral antibiotics to the child. They discharged against medical advice, so follow-up in our institution was not done. They decided they would follow-up in a private hospital that had a gynecologist. Through contact tracing of that private hospital, we found out that the prolapse had not recurred after 3 months, and the bleeding had stopped by this time. We also contacted the gynecologist that when they come for follow-up, they should watch out for vaginal stenosis as the child grows older. The relevant hospital authorities have also been informed of this case; however, we clearly stated that the etiology of the uterovaginal prolapse was undetermined.

\section{Discussion}

Uterovaginal prolapse which is a form of genital prolapse has been classified into primary and secondary [15]. It is said to be primary if caused by a congenital abnormality or if supporting tissues of the pelvis is weak and is said to be secondary if caused by extraordinary stress to normally suspended pelvic muscles as in prolonged labor or trauma to the pelvic muscles $[16,17]$.

Since this index case had not had a history of genital prolapse and a secondary cause would be secondary to an extraordinary stress on the pelvis, we had a high index of suspicion that the prolapse was secondary to sexual abuse; however, other forms of trauma like fall astride cannot be ruled out. Early treatment is necessary to avoid continuous exposure of the mucosa which can predispose to not only injury but subsequent metaplasia from prolonged exposure [3]. Differentials that could be mistaken for uterovaginal prolapse are urethral prolapse, vaginal polyps, or a vaginal rhabdomyosarcoma.

A urethral prolapse ruled out as urethral opening was seen separately from the mass, while a close differential of vaginal rhabdomyosarcoma was ruled out because the mass was reducible, and most of these tumors are associated with a pelvic tumor which was absent in this child. Other differentials were cervical or vaginal polyps. However, like rhabdomyoma or sarcomas, polyps would also not be reducible.

The acquired form of uterovaginal prolapse can follow sexual abuse, and this is of note with the increasing rate of sexual abuse of children being reported [6].

Sexual abuse has been said to be associated with pelvic floor disorders, particularly in adult females [17]. The sexually abused child too in later years may have chronic pelvic pain and fertility problems [18].

The sexual assault of a child affects not only the victim but the family also as the perpetrator could be a family member. In this respect, it is a public health problem [19].

Quite alarming is the unwillingness of the parents to investigate the likelihood of trauma to the child to be sexual abuse. This unwillingness may be due to the consequent social stigmatization of child and family from the community, denial of the parents, and an obvious communication gap between parents and child as the child is just a toddler and not able to communicate the trauma, she experienced [20].

In this index case, reduction of the prolapse was successful, and most reviewed articles on neonatal prolapse showed digital reduction (conservative management) was successful in more than $90 \%[3,4,15,16]$. Other conservative methods are the use of vaginal pessaries or 
tampons, or a two-way Foley catheter in the vagina [16, 21].

From reviewed articles, surgical options of repair are done if conservative management fails. These options from the research articles reviewed are purse-string suturing of the walls of the vagina or temporary suturing of the labia minora [22]. In intractable cases, procedures like uterine ventrosuspension sling, abdominal sacrocolpopexy, or sacral cervicopexy could be done [23]. Fortunately, in this index case, the reduction was maintained by strapping the buttocks together with a crepe bandage.

\section{Conclusion}

So, this case report highlights the importance that a clinician should be aware of uterovaginal prolapse as they may mistake it for urethral prolapse or a vaginal tumor. Also, this condition can be managed successfully using the mermaid fashion of strapping after digital reduction. It is quite simple and reproducible so this approach is recommended. This case also highlights that not all forms of uterovaginal prolapse are primary (congenital) in a child; some forms are secondary.

\section{Abbreviation \\ UVP: Uterovaginal prolapse}

\section{Acknowledgements}

We acknowledge Dr Chinunsum Issama who managed the child clinically.

\section{Authors' contributions}

All authors read and approved the final manuscript. Additional contributions were as follows: Corresponding author, lead writer, and clinical care coordinator and initial manuscript writing was by OHK. Case presentation was by NMI and OHK. Literature review of patient manuscript with follow-up of final outcome of patient for manuscript was by EPA and OHK. Discussion and final editing of manuscript was by AA and NMI.

\section{Funding}

The authors declare that this case report received no funding.

\section{Availability of data and materials}

All data underlying the results are available as part of the article, and no additional source data are required.

\section{Declarations}

\section{Ethics approval and consent to participate}

Ethical approval and consent for minor to participate in this case report and publish accompanying images was gotten from our institution, Delta State University Hospital health research ethics committee of Delta State University Teaching Hospital, Oghara, Delta State.

\section{Delsuth hrec approval number: hrec/pan/2020/043/0385.}

Ethical approval and written informed consent was obtained from parents for reduction of uterovaginal prolapse. Written informed consent and consent for their daughter to participate in this publication was obtained from the parents of the patient for publication of this case report and accompanying images. Their only worries were that facial features of the child should not be shown, and we assured them that only the perineum of the child would be shown to other physicians for increase in knowledge of this condition.

\section{Consent for publication}

Written informed consent was obtained from the parents of the patient for publication of this case report and accompanying images.

\section{Competing interests}

The authors declare that they have no competing interests.

\section{Author details}

'Department of Surgery, Delta State University Teaching Hospital, P.M.B 07, Oghara, Delta State, Nigeria. ${ }^{2}$ Department of Community Medicine, Delta State University Teaching Hospital, Oghara, Delta State, Nigeria. ${ }^{3}$ Department of Pediatrics, Delta State University Teaching Hospital, Oghara, Delta State, Nigeria.

Received: 16 November 2020 Accepted: 27 May 2021

Published online: 07 September 2021

\section{References}

1. Urdapilleta JD. Genital prolapse. Ginecol Obstet Mex. 2004;72:356-60 PMID: 15469175.

2. Prolapsed uterus- Better Health Channel https://www.betterhealth.vic.gov.a u/health/conditionsandtreatments,september 30, 2014, sited on 8, March, 2020

3. Hyginus EO, John CO. Congenital uterovaginal prolapse present at birth. J Surg Tech Case Rep. 2013;5(2):89-91. https://doi.org/10.4103/2006-8808.12 8741 PMID: 24741427; PMCID: PMC3977332.

4. Henn EW, Juul L, Van Rensburg K. Pelvic organ prolapse in the neonate: report of two cases and review of the literature. Int Urogynecol J. 2015; 26(4):613-5. https://doi.org/10.1007/s00192-014-2539-y Epub 2014 Oct 22. PMID: 25335751.

5. Ellis H. Clinical anatomy a revision and applied anatomy for clinical students. Mass: Blackwell publishing; 2006.

6. Haag L, Pathophysiology of gynecological trauma \& sexual assault. "Study. com, study.com/academy/lesson/pathophysiology-of-gynecological-traumasexual-assault.html," 14 December 2017, sited on $26^{\text {th }}$ July 2020.

7. Burgess AW, Dowdell EB, Prentky RA. Sexual abuse of nursing home residents. J Psychosoc Nurs Ment Health Serv. 2000;38(6):10-8 PMID: 10868369 .

8. Herrmann B, Banaschak S, Csorba R, et al. Physical examination in child sexual abuse, approaches and current evidence. Deutsches Arteblatt Int. 2014;111(41):692. https://doi.org/10.3238/arztebl.2014.0692.

9. Kaplan R, Adams JA, Starling SP, et al. Medical response to child sexual abuse a resource for professionals working with children and families. St. Louis: STM Learning; 2011

10. McCann J, Miyamoto S, Boyle C, et al. Healing of hymnal injuries in prepubertal and adolescent girls: a descriptive study. Pediatrics. 2007;119: e1094-106.

11. Whitcomb EL, Rortveit G, Brown JS, et al. Racial differences in pelvic organ prolapse. Obstet Gynecol. 2009;114(6):1271-7. https://doi.org/10.1097/AOG. Ob013e3181bf9cc8 PMID: 19935029; PMCID: PMC2879888.

12. American Colleges of Obstetricians and Gynecologists. Frequently asked questions, special procedures. Surgery for Pelvic Organ Prolapse. Washington, DC: American College of Obstetricians and Gynecologists; 2013. Published online Oct 2017. Reviewed Jan 2020.

13. Handa $\mathrm{VL}$, Roem J, Blomquist $\mathrm{JL}$ et al. Pelvic organ prolapse as a function of levator ani avulsion, hiatus size and strength, Am J Obstet Gynecol. 2019; 221 (1): 41.e1-41.e7. Published online 2019 Mar Doi: https://doi.org/10.1016/ j.ajog.2019.03.004. PMCID: PMC6592735

14. Svabik K, Martan M, Masata J. Vagina prolapse and levator ani avulsion injury. Female Pelvic Med Reconstr Surg. 2019;25(1):3-7. PMID: 23094768. https://doi.org/10.1097/SPV.0000000000000644.

15. Fraser RD. A case of genital prolapse in a newborn baby. Br Med J. 1961; 1(5231):1011-2. https://doi.org/10.1136/bmj.1.5231.1011 PMID: 13701527; PMCID: PMC1953210.

16. Abdelsalam SE, Desouki NM, Abd Alaal NA. Use of Foley catheter for management of neonatal genital prolapse: case report and review of the literature. J Pediatr Surg. 2006;41(2):449-52. https://doi.org/10.1016/j. jpedsurg.2005.11.031 PMID: 16481269.

17. Beck JJ, Elsevier HW, Pelger RC, et al. Multiple pelvic floor complaints are correlated with sexual abuse history. J Sex Med. 2009;6:193-19.

18. Postma R, Bicanic L, Van der Vaart $H$, et al. Pelvic floor muscle problems mediate sexual problems in young adult rape victims. J Sex Med. 2013;10: 1978-87.

19. World Health Organizations (WHO), London School of Hygiene and Tropical Medicine. Preventing intimate partner and sexual violence against women. 
Taking action and generating evidence. Geneva: World Health Organization; 2010.

20. Chandran S, Bhargava S, Rao KM. Under-reporting of child sexual abuse- the barriers guarding the silence. J Psychiatry. 2018:4(2):57-60 57. https://doi. org/10.18231/2455-8559.2018.0003.

21. Lockwood G, Durkee C, Groth T. Genital prolapse causing urinary obstruction and hydronephrosis in a neonate: a case and review of the literature. J Neonat Surg. 2012;1:39.

22. Baskaran D, Mohan $P$, Nazeeb. Purse string suturing in a neonatal prolapsed uterus. Indian J Surg. 2012; 74(2):143-145. doi: https://doi.org/10.1007/s122 62-011-0361-z. Epub 2011 Nov 18. PMID: 23543808; PMCID: PMC3309088.

23. Pirgon O, Atabek ME, Suleymanoglu S. Genital prolapse in a newborn following resection of sacrococcygeal teratoma. J Pediatr Adolesc Gynecol. 2009;22:96-8.

\section{Publisher's Note}

Springer Nature remains neutral with regard to jurisdictional claims in published maps and institutional affiliations.

\section{Submit your manuscript to a SpringerOpen ${ }^{\circ}$ journal and benefit from:}

- Convenient online submission

- Rigorous peer review

- Open access: articles freely available online

- High visibility within the field

- Retaining the copyright to your article

Submit your next manuscript at $\boldsymbol{\wedge}$ springeropen.com 